\title{
Неохлаждаемые фотодиоды для регистрации импульсного инфракрасного излучения в спектральном диапазоне 0.9-1.8 мкм
}

\author{
() Е.В. Куницына, А.А. Пивоварова, И.А. Андреев, Г.Г. Коновалов, Э.В. Иванов, \\ Н.Д. Ильинская, Ю.П. Яковлев
}

Физико-технический институт им. А.Ф. Иоффре Российской академии наук, 194021 Санкт-Петербург, Россия

E-mail: kunits@iropt9.ioffe.ru

Поступила в Редакцию 24 февраля 2021 г.

В окончательной редакции 15 марта 2021 г.

Принята к публикации 15 марта 2021 г.

\begin{abstract}
Созданы и исследованы неохлаждаемые фотодиоды на основе гетероструктур $\mathrm{GaSb} / \mathrm{GaAlAsSb}$ для регистрации импульсного инфракрасного излучения в спектральном диапазоне 0.9-1.8 мкм. Активная область GaSb была получена с использованием свинца в качестве нейтрального растворителя с целью снижения концентрации природных акцепторов. Емкость фотодиодов при диаметре чувствительной площадки 300 мкм составляла 115-135 пФ без смещения и 62-70 пФ при обратном смещении 1.5 В. Быстродействие фотодиода, измеренное в фотовольтаическом режиме с помощью InGaAsP/InP-лазера с длиной волны излучения 1.55 мкм, достигало $\tau_{0.1-0.9}=42-60$ нс. Экспериментально продемонстрировано, что созданные фотодиоды могут использоваться без охлаждения для регистрации импульсного излучения лазеров и светодиодов в ближней ИК-области спектра.
\end{abstract}

Ключевые слова: фотодиоды, GaSb/GaAlAsSb-гетероструктуры, быстродействие, лазеры, светодиоды.

DOI: $10.21883 /$ FTP.2021.07.51027.9637

\section{1. Введение}

В настоящее время длины волн 1.3 и 1.55 мкм, вблизи которых располагаются второе и третье окна прозрачности оптического волокна, используются прежде всего в современных волоконно-оптических линиях связи и волоконных телекоммуникационных системах. Технология производства оптических волокон постоянно совершенствуется, и в ближайшем будущем можно ожидать перехода к системам на основе высокочистых флюоридных и халькогенидных световодов для средней ИК-области спектра, где существенное снижение рэлеевских потерь позволит увеличить дальность передачи. Следует отметить, что спектральный диапазон 0.9-1.8 мкм используется также для задач экологии, медицины, для фармацевтического и химического анализа.

Для длин волн 1.3 и 1.55 мкм существуют источники когерентного и спонтанного излучения - лазеры и светодиоды. Разработаны твердотельные лазеры с полупроводниковой накачкой [1] и полупроводниковые лазеры на основе AlGaInAs/InP [2,3], а также InGaAsP/InP MQW структур [4]. Для создания лазеров с длиной волны излучения в диапазоне 1.25-1.65 мкм перспективные результаты были достигнуты при использовании нитридов III группы и их твердых растворов GaInNAs, GaInNAsSb, $\mathrm{AlGaN} \mathrm{[5-8].} \mathrm{Светодиоды} \mathrm{для} \mathrm{ближнего} \mathrm{ИК-диапазона}$ традиционно выпускаются на основе InGaAs и InGaAsP, однако в литературе сообщалось и о других типах таких приборов, в частности, об источниках с GaInNAs/GaAs QW резонатором [9], гибридных кремнийорганических светодиодах [10] и т.д.
Известно, что наработка до отказа и срок службы прибора определяются, в том числе, условиями и режимом его эксплуатации. Лазеры, работающие в непрерывном режиме с мощностью от нескольких мВт до нескольких Вт, могут выходить из строя вследствие тепловой перегрузки, в то время как в импульсном режиме допускается значительное перенапряжение на короткие промежутки времени без угрозы повреждения [11]. Работа светодиодов в импульсном режиме также позволяет значительно увеличить их мощность по сравнению с мощностью в квазинепрерывном режиме. Кроме того, переход ИК-лазеров и светодиодов на импульсный режим работы дает возможность повысить быстродействие оптоэлектронных систем.

Регистрация импульсного инфракрасного излучения остается одной из важных проблем лазерной физики и импульсной фотометрии, для решения которой требуется разработка быстродействующих фотоприемников. Для длин волн 1.3 и 1.55 мкм созданы Ge/Si-фотоприемники с квантовыми точками (КТ) [12-14]. В работе [13] было достигнуто увеличение квантовой эффективности $\mathrm{Ge} / \mathrm{Si}$-фотоприемника со слоями $\mathrm{Ge}-$ нанокластеров в качестве активного элемента от 3\% при нормальном падении света до $21 \%$ (1.3 мкм) и $16 \%$ (1.55 мкм) за счет его волноводной структуры.

В настоящее время в ближней ИК-области спектра широко применяются фотоприемники на основе гетероструктур InGaAs/InP, в активной области которых используется прямозонный твердый раствор $\operatorname{In}_{0.53} \mathrm{Ga}_{0.47} \mathrm{As}$, имеющий, по сравнению с непрямозонным германием, бо́льший коэффициент поглощения на длине волны 1.55 мкм и более низкую собственную концентрацию 
Параметры GaSb/GaAlAsSb-гетероструктур, выращенных на подложке $\mathrm{GaSb}(100)$

\begin{tabular}{l|c|c|c}
\hline & Подложка & \multicolumn{2}{|c}{ Эпитаксиальные слои } \\
\cline { 2 - 4 } & $\mathrm{GaSb}(100)$ & $\mathrm{GaSb}$ & $\mathrm{Ga}_{0.66} \mathrm{Al}_{0.34} \mathrm{As}_{0.025} \mathrm{Sb}_{0.075}$ \\
\hline Толщина, мкм & 300 & $5.0-5.5$ & $1.5-2.0$ \\
Легирующая примесь & $\mathrm{Te}$ & $\mathrm{Ge}$ \\
Тип проводимости & $n$ & $n$ & $(6-8) \cdot 10^{18}$ \\
Концентрация носителей заряда \\
$\begin{array}{l}\text { (типичная) при } T=300 \mathrm{~K}, \text { cм }^{-3} \\
\text { Ширина запрещенной зоны } E_{g}\end{array}$ & $1.9 \cdot 10^{17}$ & $(4-20) \cdot 10^{16}$ & 1.1 \\
при $T=300 \mathrm{~K}$, эВ & 0.72 & 0.72 &
\end{tabular}

носителей заряда [15]. На основе данных материалов недавно были разработаны быстродействующие фотоприемники с полосой пропускания до 20 ГГц при диаметре чувствительной площадки 18 мкм [16]. Полоса пропускания фотоприемников с активной областью, состоящей из нескольких эпитаксиальных слоев InGaAs с различной концентрацией, при уменьшении площади чувствительной площадки до 24 мкм $^{2}$ может достигать более 100 ГГц [17]. Однако для ряда применений, где уменьшение размера чувствительной площадки фотодиода нежелательно из-за потерь в чувствительности, необходимо искать альтернативные методы повышения быстродействия.

Промышленно InGaAs/InP-фотодиоды выпускают компании Hamamatsy (Япония) и Jenoptic (Германия) $[18,19]$. Компания ООО „Лазерском“ (Беларусь) [20] разрабатывает ріп-фотодиодные модули, предназначенные для применения в аппаратуре ВОСПИ. Российская компания ООО „АИБИ“ [21] для создания фотоприемников, работающих в спектральном диапазоне 1.1-2.4 мкм, использует систему материалов $\mathrm{GaSb}-\mathrm{InAs}$.

Недавно нами были созданы первые образцы неохлаждаемых $\mathrm{GaSb} / \mathrm{GaAlAsSb}$-фотодиодов для спектрального диапазона 1.10-1.85 мкм [22]. Одной из отличительных особенностей таких фотодиодов является низкая концентрация носителей заряда в активной области $\mathrm{GaSb}$, достигнутая за счет использования свинца в качестве нейтрального растворителя. В лучших образцах концентрация носителей заряда была снижена почти на 2 порядка величины: от $n=(2-3) \cdot 10^{17} \mathrm{~cm}^{-3}$ до $n=2 \cdot 10^{15} \mathrm{~cm}^{-3}$. В данной работе экспериментально исследуется быстродействие таких фотодиодов и рассматривается возможность их применения для регистрации импульсного излучения с длиной волны 1.55 мкм.

\section{2. Получение экспериментальных образцов и методики исследования}

Быстродействие полупроводниковых фотоприемников определяется тремя основными факторами: временем диффузии электронно-дырочных пар $t_{\text {diff }}$ к области пространственного заряда (ОПЗ), временем дрейфа носи- телей через обедненную область $t_{\mathrm{dr}}$ и временем зарядки/разрядки собственной емкости $p-n$-перехода $t_{R C}$. Снижение остаточной концентрации носителей заряда в активном слое приводит к расширению ОПЗ. В результате в $p-i-n$-фотодиодах практически отсутствует медленная диффузионная составляющая скорости фотоответа, так как генерация электронно-дырочных пар происходит непосредственно в ОПЗ. Скорость дрейфа носителей можно оценить, зная их подвижность в данном материале при комнатной температуре и значение напряженности электрического поля в ОПЗ. Так, подвижность электронов в $\mathrm{GaSb} n$-типа проводимости с различным уровнем легирования теллуром, по данным проведенного нами исследования гальваномагнитных свойств, составляет $\mu_{e} \sim 3200-6900 \mathrm{~cm}^{2} / \mathrm{Bc}$. Тогда при напряженности электрического поля $E \sim 10^{4} \mathrm{~B} / \mathrm{cm}$ минимальная скорость дрейфа $V_{\mathrm{dr}}=\mu_{e} E \sim 3 \cdot 10^{7} \mathrm{~cm} / \mathrm{c}[23]$. $\mathrm{B}$ результате для активного слоя $\mathrm{GaSb}$ толщиной 5 мкм максимальное значение $t_{\mathrm{dr}}$ составит $\sim 17$ пс, и данной величиной также можно пренебречь. Таким образом, скорость фотоответа $p-i-n$-фотодиода будет определяться временем $t_{R C}$, а именно произведением значений сопротивления нагрузки $R$ и емкости $p-n$-перехода $C_{p-n}$. Тогда для повышения быстродействия фотоприемника прежде всего необходимо снижать емкость $p-n$ перехода.

Гетероструктуры $\mathrm{GaSb} / \mathrm{GaAlAsSb}$ для создания $p-i-n$-фотодиода выращивались методом жидкофазной эпитаксии на подложках $n-\mathrm{GaSb}(100)$, легированных Те до концентрации носителей $1.9 \cdot 10^{17} \mathrm{~cm}^{-3}$ (см. таблицу). Для снижения концентрации носителей активная область $\mathrm{GaSb}$ была получена с использованием свинца в качестве нейтрального растворителя. Данный метод позволяет уменьшить концентрацию природных структурных дефектов в $\mathrm{GaSb}$ и в твердых растворах на его основе за счет изменения соотношения атомных долей сурьмы и галлия в растворе-расплаве. С другой стороны, получение материала активной области с низкой концентрацией дефектов, в котором эффективное

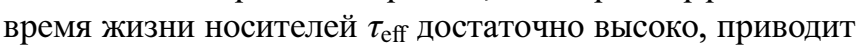
к снижению объемной составляющей обратного темнового тока фотодиода и, соответственно, уровня шумов. 
Толщина активной области $n$-GaSb для разных образцов гетероструктур составляла $5.0-5.5$ мкм, широкозонного „окна“ $p$-GaAlAsSb - 1.5-2.0 мкм. При увеличении толщины эпитаксиального слоя $\mathrm{GaSb}$ до 25 мкм и более наблюдалось нарушение процесса роста слоя GaAlAsSb: на поверхности гетероструктуры наблюдались пирамиды с $X$-образным основанием. Данное явление связано с нарушением стехиометрии поверхности эпитаксиального слоя $\mathrm{GaSb}$, выращенного из свинцовых раствороврасплавов, при больших толщинах данного слоя.

С целью получения материала $n$-типа проводимости активная область $\mathrm{GaSb}$, выращенная с использованием свинца, легировалась теллуром для изменения концентрации основных носителей в широком диапазоне $n=(4-20) \cdot 10^{16} \mathrm{~cm}^{-3}$ (см. таблицу). Это позволило нам провести исследования электролюминесцентных характеристик образцов с различным уровнем легирования и оценить влияние теллура на данные характеристики. Широкозонное „окно“ $\mathrm{Ga}_{0.66} \mathrm{Al}_{0.34} \mathrm{As}_{0.025} \mathrm{Sb}_{0.97}$ легировалось германием до концентрации $p=(6-8) \cdot 10^{18} \mathrm{~cm}^{-3}$.

На основе выращенных гетероструктур $\mathrm{GaSb} /$ $\mathrm{GaAlAsSb}$ методами контактной фотолитографии и жидкостного химического травления были созданы чипы размером $500 \times 500$ мкм. Фоточувствительная площадка (меза) имела форму образующейся капли (несферической) с диаметром основной части 300 мкм (см. рис. $1, a$ ). Омический контакт в форме треугольника для материала $p$-типа создавался методом взрывной фотолитографии и термического напыления системы $\mathrm{Cr} / \mathrm{Au} / \mathrm{Ni} / \mathrm{Au}$ в высоковакуумной установке. Далее проводилось усиление напыленного контакта методом электрохимического осаждения Аu до толщины 2.0 мкм. Для материала $n$-типа со стороны подложки $\mathrm{GaSb}$ проводилось напыление сплошного слоя системы $\mathrm{Cr} / \mathrm{Au} / \mathrm{Ni} / \mathrm{Au}$ с последующим напылением $\mathrm{Cr} / \mathrm{Au}$ до толщины 0.6 мкм. Фотодиодные чипы монтировались на стандартные корпуса ТО-18, для проведения температурных измерений - на корпуса TO-5 с термоэлектрическим модулем.

Боковая поверхность мезы с выходом на $p-n$-переход (см. pис. $1, b$ ) защищалась анодным окислом. Процесс проводился при постоянном напряжении $U=60 \mathrm{~B}$, в состав электролита входили винная кислота $(0.3 \%)$ и этиленгликоль в соотношении $1: 2$. Известно, что толщина анодного окисла зависит от типа проводимости полупроводника и концентрации носителей заряда. В результате исследования скола гетероструктур $\mathrm{GaSb} / \mathrm{GaSb} / \mathrm{GaAlAsSb}$ с помощью микроскопа MikroZoom II было обнаружено, что эпитаксиальные слои окисляются однородно, и возможно получение равномерного окисла достаточной толщины $\sim 1000 \AA$. Удельное сопротивление такого окисла, по нашим оценкам, составляло 200 Ом·см. Таким образом, снижение концентрации носителей в активной области $\mathrm{GaSb}$ при высокой концентрации в Al-содержащем слое не влияет существенно на толщину получаемого окисла, и этот метод был использован для пассивации $p-n$-перехода.
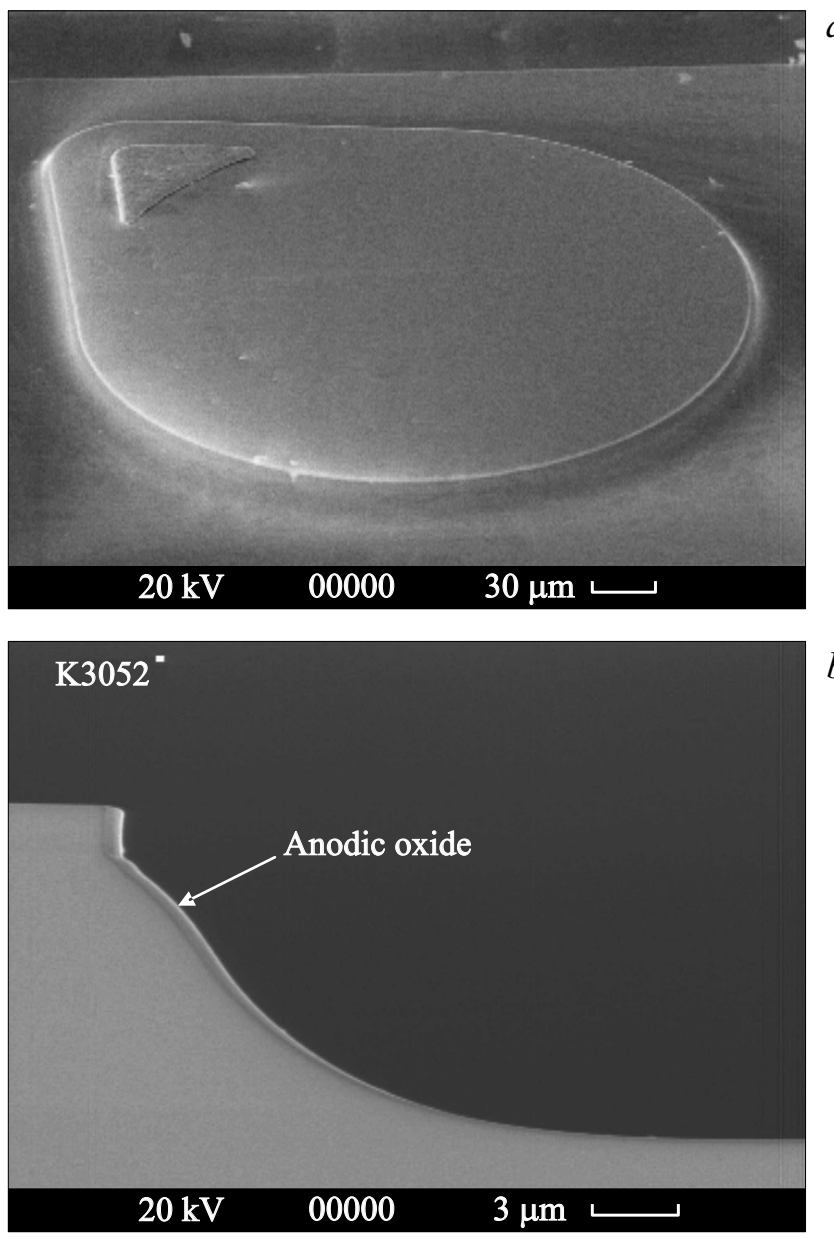

Рис. 1. РЭМ-изображение мезы фотодиода на основе гетероструктуры GaSb/GaAlAsSb: $a$ - лицевая фоточувствительная поверхность с напыленным омическим контактом; $b-$ профиль боковой поверхности мезы.

Вольт-амперные характеристики (ВАХ) фотодиодов исследовались с помощью автоматизированного измерителя. Напряжение источника питания изменялось дискретно с шагом $0.05 \mathrm{~B}$. Графики ВАХ и значения напряжения и тока выводились на монитор компьютера в режиме реального времени.

При измерении спектров фоточувствительности фотодиодов использовалась схема синхронного детектирования, включающая призменный монохроматор SPM2 (Carl Zeiss), механический модулятор и селективный усилитель SR830 (Stanford Research). Частота модуляции излучения составляла 500 Гц. Для измерения величины фототока исследуемые фотодиоды подключались в фотогальваническом режиме с нагрузочным сопротивлением 100 Ом, так как исследуемые приборы имеют дифференциальное сопротивление $>10$ кОм в нуле смещения. Для определения токовой монохроматической чувствительности $S_{I}\left(\lambda_{\max }\right)$ использовался метод сравнения с калиброванным приемником излучения. 
Вольт-фарадные характеристики (ВФХ) фотодиодов исследовались с помощью цифрового измерителя иммитанса (RLC) E7-12 (Agilent Technology). Измерение емкости проводилось мостовым методом по ГОСТ 18986.4-73 (75) на частоте $f=1$ МГц при сопротивлении нагрузки $R_{L}=51$ Ом и напряжении обратного смещения до $U_{\text {rev }}=-1.5 \mathrm{~B}$.

Времена нарастания $\tau_{\text {rise }}$ и спада $\tau_{\text {fall }}$ импульса фотоответа, определяющие быстродействие фотодиодов, измерялись при помощи $\mathrm{InGaAsP} / \mathrm{InP}$-лазера с длиной волны излучения $\lambda=1.55$ мкм.

\section{3. Экспериментальные результаты и обсуждение}

Для качественной оценки наличия структурных дефектов в активной области фотодиодных гетероструктур $\mathrm{GaSb} / \mathrm{GaAlAsSb}$ были проведены исследования электролюминесцентных характеристик. Как видно из рис. 2, при $T=300 \mathrm{~K}$ спектры излучения состоят из двух полос, для основной из которых максимум интенсивности соответствует длине волны $\lambda=1.72$ мкм $(h v=0.72$ эВ $)$ при токе $I=100$ мА. С увеличением тока до $I=200$ мА основной максимум смещается в длинноволновую область на $\Delta \lambda=0.02$ мкм. При этом ширина полосы излучения на половине высоты $(F W H M)$ изменяется от 0.20 до 0.22 мкм, что говорит о незначительном влиянии разогрева на электролюминесцентные характеристики при протекании питающего тока. Основная полоса излучения соответствует межзонной излучательной рекомбинации в активной области $\mathrm{GaSb}\left(E_{g}=0.72\right.$ эВ $)$.

Интенсивность второго пика $\lambda=1.94$ мкм (энергия фотона 0.64 эВ), как наблюдалось нами для образцов с различным уровнем легирования, не зависит от концентрации Те и, предположительно, определяется участием в генерации излучения двухзарядных акцепторов, образующихся при размещении $\mathrm{Ga}$ в узлах $\mathrm{Sb}$ кристаллической решетки. Так как интенсивность данного пика

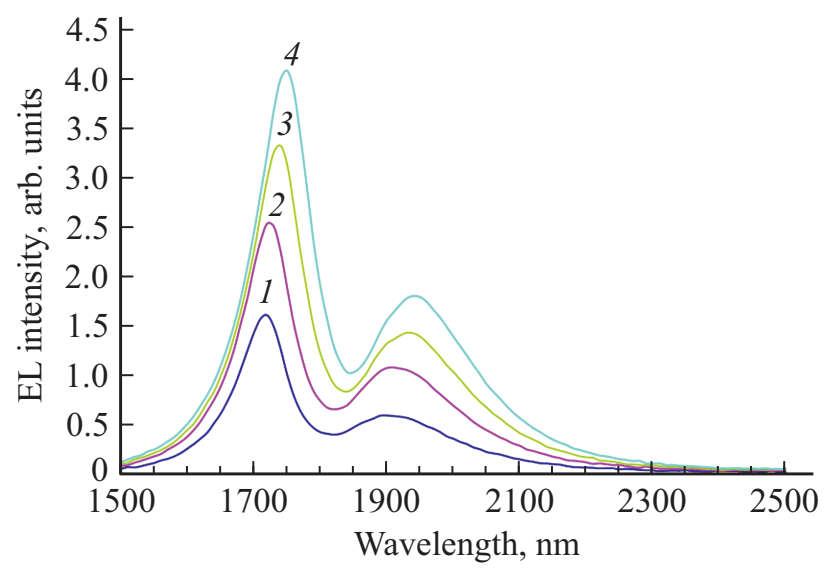

Рис. 2. Спектр электролюминесценции гетероструктуры $\mathrm{GaSb} / \mathrm{GaAlAsSb}$ при различных токах накачки $I, \mathrm{MA:} 1-50$, $2-100,3-150,4-200$.
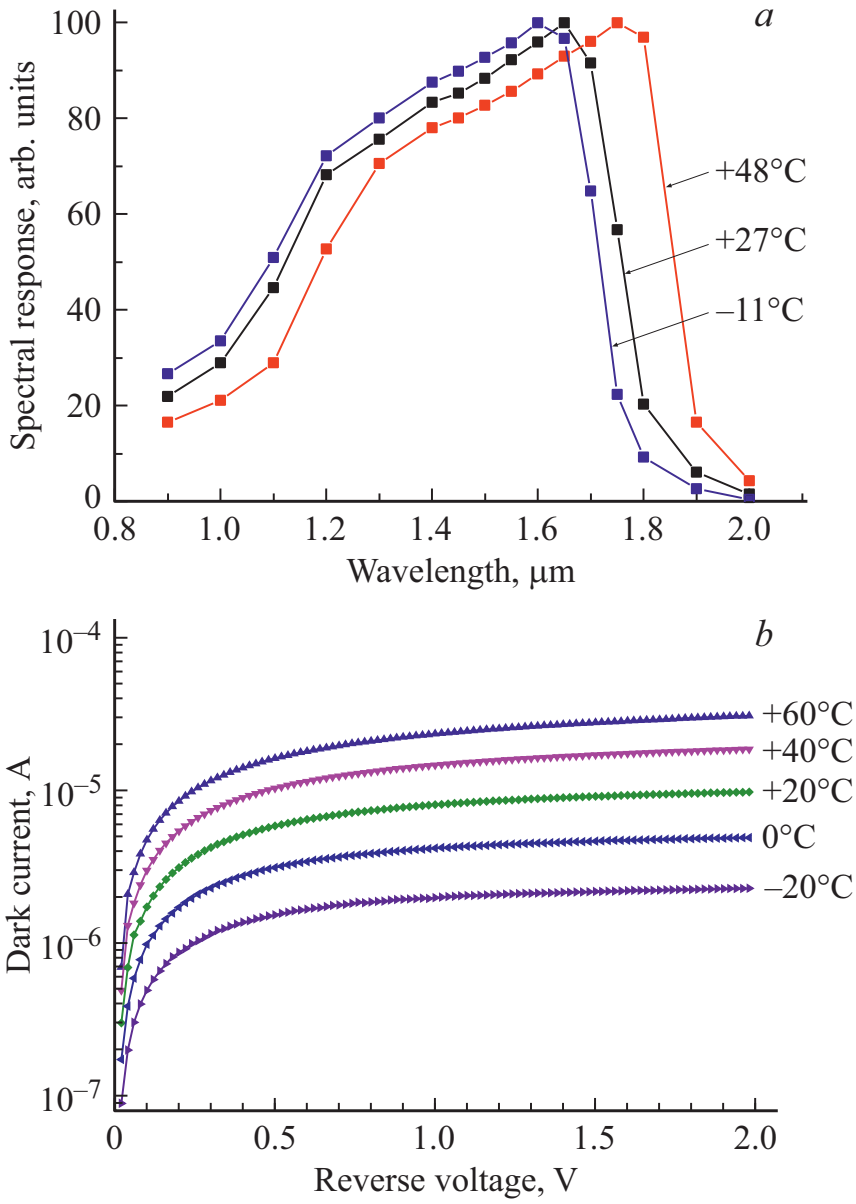

Рис. 3. Спектральные и электрические характеристики $\mathrm{GaSb} / \mathrm{GaAlAsSb-фотодиода} \mathrm{с} \mathrm{диаметром} \mathrm{фоточувствительной}$ площадки 300 мкм при различных температурах: $a$ - распределение спектральной чувствительности; $b-$ вольт-амперные характеристики (обратная ветвь).

достаточно велика (0.42 от интенсивности основного пика при $I=200$ мА), можно сделать вывод о том, что несмотря на снижение концентрации носителей в $\mathrm{GaSb}$ за счет использования свинца в качестве нейтрального растворителя, влияние природных акцепторов все еще остается существенным фактором.

Зависимость спектральной чувствительности фотодиодов на основе гетероструктур $\mathrm{GaSb} / \mathrm{GaAlAsSb}$ от длины волны при $T=-11-+48^{\circ} \mathrm{C}$ представлена на рис. 3, $a$. При комнатной температуре фотодиоды имеют спектральную чувствительность (не менее 10\% от максимума) в диапазоне от 0.9 до 1.85 мкм, при этом максимальная чувствительность (более $80 \%$ ) наблюдается в области 1.33-1.72 мкм.

На рис. 3, $b$ приведены вольт-амперные характеристики исследуемых $\mathrm{GaSb} / \mathrm{GaAlAsSb-фотодиодов} \mathrm{при} \mathrm{различ-}$ ных температурах $\left(T=-20-+60^{\circ} \mathrm{C}\right)$. Как видно из рисунка, при комнатной температуре типичная величина обратного темнового тока составляет $I_{D}=5 \cdot 10^{-6} \mathrm{~A}$ вблизи $U=0 \mathrm{~B}$. 

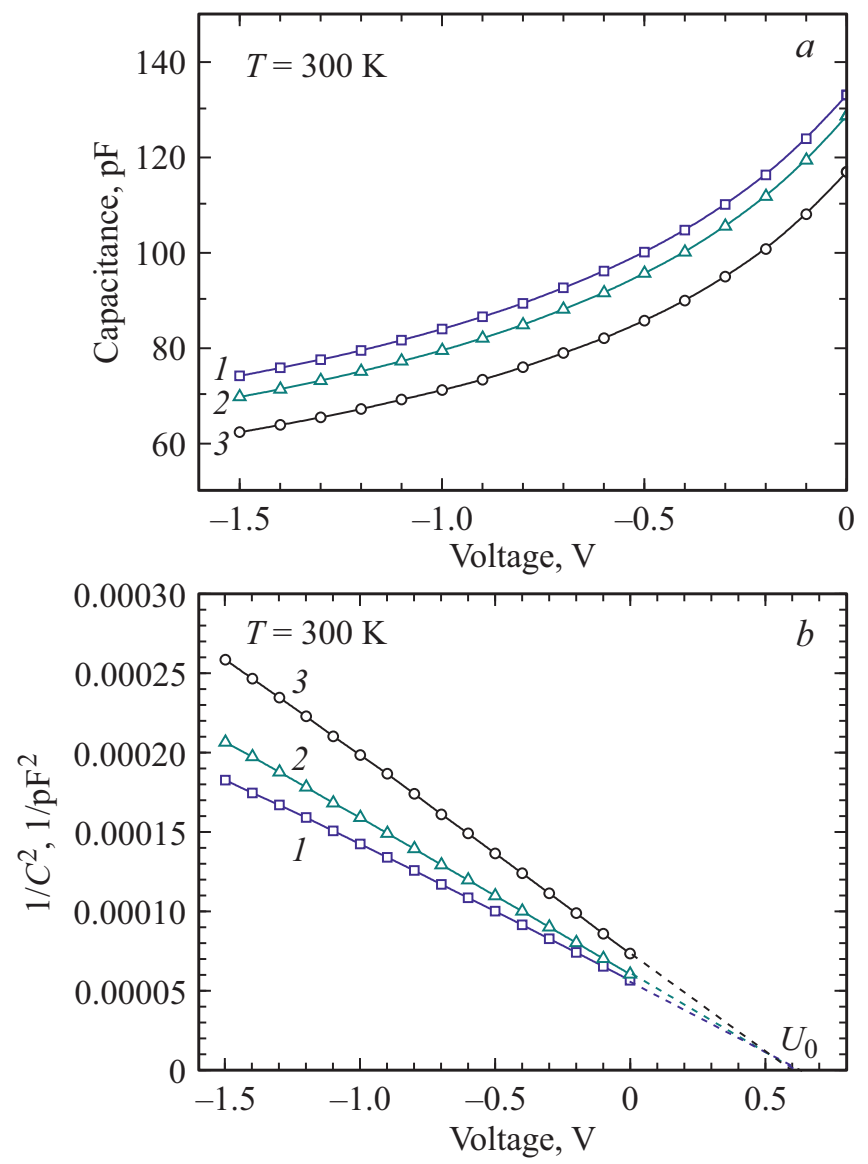

Рис. 4. Вольт-фарадные характеристики $\mathrm{GaSb} / \mathrm{GaAlAsSb-фото-}$ диодов (образцы $1-3$ ) с диаметром фоточувствительной площадки 300 мкм $(a)$ и зависимость $C^{-2}=f(U)(b)$ при комнатной температуре.

Исследование вольт-фарадных характеристик (ВФХ) показало, что при диаметре фоточувствительной площадки 300 мкм типичная емкость фотодиода составляет $C=115-135$ пФ без смещения и $C=62-75$ пФ при обратном смещении $U_{\mathrm{rev}}=-1.5 \mathrm{~B}$ (см. рис. 4, $a$ ). Для данных фотодиодов наблюдалась обратная квадратичная зависимость емкости от приложенного напряжения $C^{-2}=f(U)$, что говорит о резком распределении примесей в гетероструктуре (см. рис. $4, b$ ). Контактная разность потенциалов на $p-n$-переходе (в вольтах), экспериментально определенная из данных графиков, составляет $U_{0}=0.6 \mathrm{~B}$.

Известно, что емкость фотодиода $C$ состоит из емкости $p-n$-перехода $C_{p-n}$ и паразитной емкости $C_{p}$. Величина $C_{p-n}$ также является суммой двух компонент барьерной $C_{b}$, связанной с изменением потенциального барьера, и диффузионной $C_{\text {diff, }}$ определяемой прямым током через $p-n$-переход и имеющую частотную зависимость. При обратных напряжениях $C_{b}$ значительно превышает $C_{\text {diff. }}$ Тогда при работе фотодиода в фотовольтаическом либо фотодиодном режиме, т.е. без смещения либо с приложением обратного смещения, можно считать, что $C_{p-n}=C_{b}$. При этом $C_{b}$ фотодиода, определяемая конструктивными особенностями корпуса прибора и выводов, составляет величину $<0.5$ пФ, и ею можно пренебречь.

Барьерная емкость $p-n$-перехода $C_{b}$ определяется в соответствии с формулой для плоского конденсатора, в которой за расстояние между обкладками конденсатора принимается ширина ОПЗ: $C_{b}=\varepsilon_{0} \varepsilon A / W$, где $A-$ площадь $p-n$-перехода, $W-$ ширина ОП $3, \varepsilon_{0}$ - диэлектрическая постоянная, $\varepsilon-$ относительная диэлектрическая проницаемость полупроводника. Основное отличие состоит в том, что $W$ не является постоянной величиной и по своему значению приближается к толщине $i$-слоя (активной области фотодиода) только в случае полного обеднения последнего при приложении напряжения смещения. Для асимметричного $p-n$-перехода, $p$-область которого легирована значительно сильнее $n$-области $\left(N_{D} \ll N_{A}\right.$, см. таблицу), ширина ОПЗ описывается выражением: $W=\left[2 \varepsilon_{0} \varepsilon\left(\varphi_{p-n}+e U_{\text {rev }}\right) / e^{2} N_{D}\right]^{1 / 2}$, где $U_{\text {rev }}-$ напряжение обратного смещения, $\varphi_{p-n}-$ разность потенциалов на $p-n$-переходе (высота потенциального барьера $p-n$-перехода без смещения, эВ), $N_{D}-$ концентрация остаточных доноров в активной области (при комнатной температуре $N_{D}=n_{0}$, где $n_{0}-$ концентрация основных носителей). Следует отметить, что для гетероперехода, в отличие от гомоперехода, значения диэлектрических проницаемости для $n$ - и $p$-областей будет несколько различаться.

Как упоминалось в разд. 2, для $p-i-n-$ $\mathrm{GaSb} / \mathrm{GaAlAsSb-фотодиодов} \mathrm{скорость} \mathrm{фотоответа}$ определяется $R C$-компонентой, а именно временем зарядки/разрядки собственной емкости $p-n$-перехода $t_{R C}$. При малых токах дифференциальное сопротивление фотодиода $R_{\text {diff }}$ оказывается существенным. Так, величина дифференциального сопротивления, оцененная по ВАХ, для различных образцов фотодиодов составляет $R_{0}=30-50$ кОм при $U=0 \mathrm{~B}$ и $T=300 \mathrm{~K}$. Однако в области бо́льших токов дифференциальное сопротивление фотодиода $R_{\text {diff }}$ относительно мало, и в классическом случае его значением можно пренебречь. Тогда при работе на нагрузку $R_{L}=51$ Ом и обратном смещении $1.5 \mathrm{~B}$ ширина полосы пропускания $\Delta f$, рассчитанная по формуле $\Delta f=1 /\left(2 \pi R_{L} C\right)$, имеет значение $42-51 \mathrm{MГц.} \mathrm{Время} \mathrm{нарастания} \mathrm{импульса}$ оценивается как $t_{\text {rise }}=0.35 / \Delta f=7-8$ нс. Данная расчетная величина согласуется с нашими первыми оценками времени отклика $\mathrm{GaSb} / \mathrm{GaAlAsSb}$-фотодиодов, приведенными в работе [22]. Таким образом, расчетное значение быстродействия фотодиода составляет $\tau_{0.1-0.9}=t_{\text {rise }}=7-8 \mathrm{Hc}$.

Быстродействие фотодиода исследовалось экспериментально на длине волны $\lambda=1.55$ мкм с помощью InGaAsP/InP-лазера (исходный импульс длительностью $\tau=300$ нс, время нарастания импульса $\tau_{\text {rise }}=30$ нс). Для различных образцов фотодиодов измеренное время нарастания импульса фотоответа $t_{\text {rise }}$ лежало в пределах 54-62 нс и время спада импульса составляло 


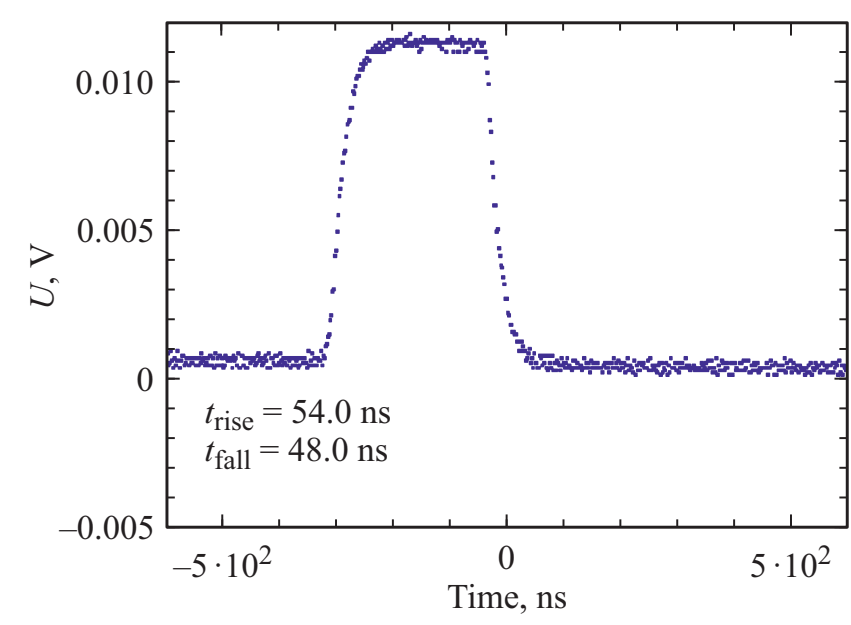

Рис. 5. Импульс фотоответа $\mathrm{GaSb} / \mathrm{GaAlAsSb-фотодиода} \mathrm{при}$ детектировании импульсного излучения лазера с длиной волны $\lambda=1.55$ мкм, длительностью импульса $\tau=300$ нс, временем нарастания импульса $\tau_{\text {rise }}=30$ нс.

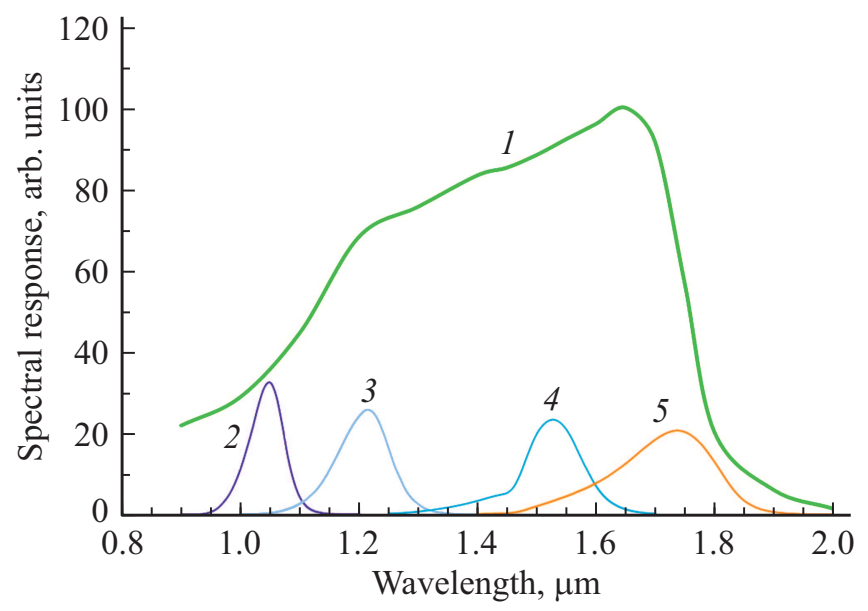

Рис. 6. Спектральная характеристика $\mathrm{GaSb} / \mathrm{GaAlAsSb-фото-}$ диода (1) и спектры излучения светодиодов с максимумом интенсивности на длине волны $\lambda$, мкм: 1.05 (2), 1.21 (3), $1.53(4), 1.74(5)$.

$t_{\text {fall }}=42-60$ нс (см. рис. 5). Так как за быстродействие фотоприемника $\tau_{0.1-0.9}$ принимается либо $t_{\text {rise }}$, либо $t_{\text {fall }}$, допустимо считать, что измеренное быстродействие $\mathrm{GaSb} / \mathrm{GaAlAsSb-фотоприемника} \mathrm{составляет}$ $\tau_{0.1-0.9}=42-60$ нс. При уменьшении длительности и времени нарастания исходного импульса до $\tau=110$ нс и $\tau_{\text {rise }}=4$ нс соответственно значительного уменьшения $t_{\text {rise }}$ и $t_{\text {fall }}$ фотодиода не происходило. Таким образом, измеренная величина $\tau_{0.1-0.9}$ в $6-7$ раз превосходит расчетное значение. Мы полагаем, что данное расхождение можно объяснить поведением двухзарядных природных акцепторов при зарядке/разрядке собственной емкости $p-n$-перехода. Как показали исследования электролюминесцентных характеристик (см. выше), концентрация природных акцепторов в активной области прибора остается существенным фактором.

Наши исследования показали, что GaSb/GaAlAsSbфотодиод может использоваться для детектирования импульсного излучения существующих светодиодов в диапазоне 0.9-1.8 мкм. На рис. 6 представлены спектры излучения светодиодов с максимумом на длинах волн $\lambda$ : $1.05,1.21,1.53,1.74$ мкм. Как видно из рисунка, спектры данных светодиодов располагаются в пределах границ спектральной чувствительности исследуемого фотодиода не ниже уровня 20\% от ее максимума.

\section{4. Заключение}

Созданы и исследованы неохлаждаемые $\mathrm{GaSb} /$ $\mathrm{GaAlAsSb-фотодиоды.} \mathrm{При} \mathrm{комнатной} \mathrm{температуре} \mathrm{фо-}$ тодиоды демонстрируют спектральную чувствительность (не менее $10 \%$ от максимальной) в диапазоне от 0.9 до 1.85 мкм.

Спектры электролюминесценции приборов состояли из двух полос с максимумом интенсивности на длинах волн 1.72 и 1.94 мкм. Основная полоса $\lambda=1.72$ мкм соответствует межзонной излучательной рекомбинации в активной области $\mathrm{GaSb}\left(E_{g}=0.72\right.$ эВ), вторая полоса, предположительно, определяется излучением двухзарядных акцепторов. Интенсивность второго пика достаточно велика (0.42 от интенсивности основного пика при $I=200$ мА), что говорит о заметном влиянии структурных дефектов и необходимости дальнейшего снижения их концентрации в материале активной области фотодиода.

Исследование вольт-фарадных характеристик показало, что для исследуемых фотодиодов наблюдается обратная квадратичная зависимость емкости от приложенного напряжения $C^{-2}=f(U)$, что подтверждает резкое распределение примесей в гетероструктуре. Емкость фотодиодов при диаметре чувствительной площадки $d=300$ мкм имеет величину $C=115-135$ пФ без смещения и $C=62-70$ пФ при обратном смещении $U_{\text {rev }}=1.5 \mathrm{~B}$.

Быстродействие фотодиода исследовалось с помощью InGaAsP/InP-лазера с длиной волны излучения $\lambda=1.55$ мкм. Измеренная величина быстродействия $\tau_{0.1-0.9}=42-60$ нс (без смещения) превышает расчетное значение в 6-7 раз. Мы полагаем, что данное расхождение может быть связано с поведением двухзарядных природных акцепторов при зарядке/разрядке собственной емкости $p-n$-перехода. Продемонстрировано, что созданные неохлаждаемые фотодиоды могут использоваться для регистрации импульсного излучения лазеров и светодиодов в ближней ИК-области спектра.

\section{Благодарности}

Авторы выражают благодарность С.И. Трошкову за создание РЭМ-изображений $\mathrm{GaSb} / \mathrm{GaAlAsSb-фотодиодов.}$ 


\section{Конфликт интересов}

Авторы заявляют, что у них нет конфликта интересов.

\section{Список литературы}

[1] М.О. Искандаров, А.А. Никитичев, М.А. Свердлов, А.Л. Тер-Мартиросян. Науч. приборостроение, 25 (3), 124 (2015).

[2] L. Hou, S. Tang, B. Hou, S. Liang, J.H.H. Marsh. IEEE J. Select. Top. Quant. Electron., 24 (6), 1102508 (2018).

[3] А.А. Мармалюк, Ю.Л. Рябоштан, П.В. Горлачук, М.А. Ладугин, А.А. Падалица, С.О. Слипченко, А.В. Лютецкий, Д.А. Веселов, Н.А. Пихтин. Квант. электрон., 47 (3), 272 (2017).

[4] G. Belenky, L. Shterengas, C.W. Trussell, C.L. Reynolds, Jr., M.S. Hybertsen, R. Menna. In: Future Trends in Microelectronics: The Nano Millennium, ed. by S. Luryi, J. Xu, A. Zaslavsky (N.Y., Wiley Interscience, 2002) p. 231.

[5] A.Y. Egorov, D. Bernklau, B. Borchert, S. Illek, D. Livshits, A. Rucki, M. Schuster, A. Kaschner, A. Hoffmann, G. Dumitras, M.C. Amann, H. Riechert. J. Cryst. Growth, 227-228, 545 (2001).

[6] S.R. Bank, M.A. Wistey, H.B. Yuen, L.L. Goddard, H.P. Bae, J.S. Harris. J. Vac. Sci. Technol. B, 23 (3), 1337 (2005).

[7] J.W. Ferguson, P. Blood, P.M. Smowton, H. Bae, T. Sarmiento, J.S. Harris, N. Tansu, L.J. Mawst. IEEE J. Quant. Electron., 47 (6), 870 (2011).

[8] Е.В. Луценко, Н.В. Ржеуцкий, А.Г. Войнилович, И.Е. Свитенков, А.В. Нагорный, В.А. Шуленкова, Г.П. Яблонский, А.Н. Алексеев, С.И. Петров, Я.А. Соловьёв, А.Н. Петлицкий, Д.В. Жигулин, В.А. Солодуха. Квант. электрон., 49 (6), 540 (2019).

[9] M.M. Bajo, A. Guzmán, A. Trampert, A. Hierro. Solid-State Electron., 54 (4), 492 (2010).

[10] R.J. Curry, W.P. Gillin, M. Somerton, A.P. Knights, R. Gwilliam. In: Organic Light-Emitting Materials and Devices IV, ed. by Z.H. Kafafi [Proc. SPIE, 4105, 265 (2001)].

[11] W. Reeb. www.azimp.ru/articles/applications/38538/

[12] M. Elcurdi, P. Boucaud, S. Sauvage. Appl. Phys. Lett., 80, 509 (2002).

[13] А.И. Якимов, А.В. Двуреченский, В.В. Кириенко, А.И. Никифоров. ФТТ, 47 (1), 37 (2005).

[14] K.A. Lozovoy, A.V. Voytsekhovskiy, A.P. Kokhanenko, V.G. Satdarov, O.P. Pchelyakov, A.I. Nikiforov. Opto-Electron. Rev., 22 (3), 171 (2014).

[15] И.Б. Чистохин, К.С. Журавлев. Успехи прикл. физики, 3 (1), 85 (2015).

[16] O.A. Kozyreva, Y.V. Solov'ev, I.S. Polukhin, A.K. Mikhailov, G.A. Mikhailovskiy, M.A. Odnoblyudov, E.Z. Gareev, E.S. Kolodeznyi, I.I. Novikov, L.Ya. Karachinsky, A.Yu. Egorov, V.E. Bougrov. IOP Conf. Ser.: J. Physics: Conf. Ser., 917, 052029 (2017).

[17] K. Sun, A. Beling. Appl. Sci., 9 (4), 623 (2019).

[18] www.hamamatsu.com

[19] www.jenoptik.com

[20] www.laserscom.com

[21] www.ibsg.ru

[22] Е.В. Куницына, И.А. Андреев, Г.Г. Коновалов, Э.В. Иванов, А.А. Пивоварова, Н.Д. Ильинская, Ю.П. Яковлев. ФТП, $52(9), 116$ (2018).
[23] И.А. Андреев, О.Ю. Серебренникова, Г.С. Соколовский, В.В. Дюделев, Н.Д. Ильинская, Г.Г. Коновалов, Е.В. Куницына, Ю.П. Яковлев. ФТП, 47 (8), 1109 (2013).

Редактор А.Н. Смирнов

\section{Uncooled photodiodes for detecting pulsed infrared radiation in the spectral range of $0.9-1.8 \mu \mathrm{m}$}

\section{E.V. Kunitsyna, A.A. Pivovarova, I.A. Andreev, G.G. Konovalov, E.V. Ivanov, N.D. Il'inskaya, Yu.P. Yakovlev}

loffe Institute, 194021 St. Petersburg, Russia

Abstract Uncooled $\mathrm{GaSb} / \mathrm{GaAlAsSb}$ photodiodes for detecting pulsed infrared radiation in the spectral range of $0.9-1.8 \mu \mathrm{m}$ have been developed. Active GaSb layer was grown using lead as a neutral solvent in order to reduce the concentration of natural acceptors. The capacity of the photodiodes with a diameter of photosensitive area of $300 \mu \mathrm{m}$ was $C=115-135 \mathrm{pF}$ with no bias and $C=62-70 \mathrm{pF}$ at $U=-1.5 \mathrm{~V}$. The photodiode speed of response measured using an InGaAsP/InP laser with a wavelength of $1.55 \mu \mathrm{m}$ reached $\tau_{0.1-0.9}=42-60 \mathrm{~ns}$ in the photovoltaic mode. It is shown experimentally that the photodiodes can be used without cooling to detect the pulsed radiation of lasers and LEDs in the near-infrared region of the spectrum. 